\title{
Morphological characterization and genetic analysis of tri-pistil trait, a precisely regulated pistil number mutation in bread wheat
}

Tianxiang Liu

Northwest Agriculture and Forestry University

\section{Yulin Sun}

UBC: The University of British Columbia

Chao Ma

Northwest Agriculture and Forestry University

Wenhui Jiang

Chinese Academy of Agricultural Sciences Agricultural Genomes Institute at Shenzhen

Hongqi Wu

Northwest Agriculture and Forestry University

\section{Qinqin Jiang}

Northwest Agriculture and Forestry University

Enshi Xiao

Northwest Agriculture and Forestry University

Yong Wang

Northwest Agriculture and Forestry University

Zhensheng Kang

Northwest Agriculture and Forestry University

Xue Shi

Northwest Agriculture and Forestry University

Zhonghua Wang ( $\boldsymbol{\nabla}$ zhonghuawang@nwafu.edu.cn )

Northwest Agriculture and Forestry University https://orcid.org/0000-0001-5470-3092

\section{Research Article}

Keywords: tri-pistil, morphology, fine-mapping, floral homeotic genes, wheat

Posted Date: January 13th, 2022

DOI: https://doi.org/10.21203/rs.3.rs-1217258/v1 
License: (c) (i) This work is licensed under a Creative Commons Attribution 4.0 International License. Read Full License 


\section{Abstract}

Bread wheat (Triticum aestivum L.) is an important source of nutrients for humans. Therefore, improvement of its yields is essential to feed the increasing world population. The tri-pistil (TRP) trait in wheat has a high potential for increasing yields. We obtained a pure tri-pistil wheat line, 4045 , and evaluated its morphological properties. The 4045 wheat line stably produced three independently inherited pistils, which led to 1-3 grains in each floret. Among the three pistils, two lately emerged pistils initiated at late anther primordia stage to early tetrads stage. Genetic analysis revealed that there were TRP penetrance variations among the $11 \mathrm{~F}_{1}$ populations of 4045 . Fine mapping narrowed the single dominant TRP locus to a $97.3 \mathrm{~kb}$ region, containing two candidate genes, on the $2 \mathrm{DL}$ chromosome. However, further gene sequence, functional as well as comparative genomic analyses ruled out the only two candidate genes. Therefore, $T R P$ is high-likely a unique gain-of-function mutation that does not exist in normal wheat genome. Transcriptome analysis of floral homeotic genes revealed that expressions of the C-class TaAG-2s, which are essential for carpel specification, significantly increased in 4045, implying that TaAG-2s have played important roles in TRP-regulated tri-pistil formation. This study highlights that $T R P$ leads to a precisely regulated pistil number increase (PRPNI) mutations and proposed a regulatory model of PRPNI pistil architecture. PRPNI offers a novel abnormal pistil development resource for research of floral architectures and potential on crop yield improvement.

\section{Key Message}

This study defined the tri-pistil trait as a precisely regulated pistil number increase (PRPNI) type mutation; fine-mapped the TRP locus and revealed that TRP is high-likely a gain-of-function gene.

\section{Introduction}

Bread wheat (Triticum aestivum L.), which is globally consumed, accounts for approximately one-fifth of food sources for human beings (Asseng et al. 2020). Due to the constantly increasing global population, there is a need to develop crops with higher yields. However, since the Green Revolution, genetic gain rates in grain yields have been decreasing. Therefore, new resources and breeding approaches are required to improve grain yields (Foulkes et al. 2011; Molero et al. 2019). Grain number per spike (GNPS) is a crucial grain yield factor, the increase of which is an important strategy for improving wheat yield potential (Calderini et al. 2021; Foulkes et al. 2011; Molero et al. 2019).

In 1973, Chen et al. (1983) reported three wheat-grain combinations, three or two tightly combined grains, on the air-drying field of breeding materials. Seeds were saved and developed into a pure wheat line, referred to as the "tri-grain wheat". Within the past fifty years, studies evaluated floral morphologies, genetic make-up, biochemical features, and gene mapping of similar tri-pistil mutants, which were subsequently referred to as "multi-ovary" (MOV), "multiple-pistil" (MP), and "three-pistil" (TP) (Chen et al. 1999; Guo et al. 2019; Li et al. 2020c; Mahlandt et al. 2021; Peng et al. 2008; Wang et al. 2005; Wang et al. 1990; Yu et al. 2020). The tri-pistil mutants generate normal stamens and other floral organs, except for 
three fertile pistils (Li et al. 2020c; Mahlandt et al. 2021; Peng 2003). When crossed with normal lines, all $F_{1}$ plants from different cross groups exhibited a tri-pistil trait. Additionally, segregation of the $F_{2}$ population exhibited a 3:1 or 1:2:1 ratio, implying that the tri-pistil trait is controlled by a single dominant gene (Mahlandt et al. 2021; Peng 2003; Peng et al. 2008; Yu et al. 2020). Studies have used different strategies to investigate gene loci of the tri-pistil trait (Mahlandt et al. 2021; Peng et al. 2008; Peng et al. 2004; Yang et al. 2017; Yu et al. 2020; Zhu et al. 2019). It has been reported that the candidate gene is located on the long arm of the 2D chromosome (Mahlandt et al. 2021; Peng et al. 2008; Yang et al. 2017; Yu et al. 2020; Zhu et al. 2019). However, the candidate gene has not been identified. Since floral organ architectures influence plant reproductive success and is a key agronomic factor determining yield, studies on tri-pistil wheat may elucidate on wheat floral establishment mechanisms and inform on viable approaches for increasing wheat yields.

Floral homeotic MADS-box genes, most of which belong to ABCDE class genes, play a critical role in floral architectures of most angiosperms (Callens et al. 2018; Theißen 2001). In flowers of monocot plants like rice and wheat, lemma and palea in whorl 1 are specified by $A$ and $E$ class protein complexes, lodicules in whorl 2 are specified by $A, B$, and $E$ class protein complexes, while stamens in whorl 3 are specified by $B$, $\mathrm{C}$, and $\mathrm{E}$ class protein complexes. In whorl $4, \mathrm{C}$ and $\mathrm{E}$ class protein complexes, along with another regulator, Dropping Leaf (DL) specify carpels (pistils), and D and E class proteins specify ovules (Callens et al. 2018; Ito 2019; Shen et al. 2021). The roles of AG-like $C$ class genes or $D L$ in pistil specification have not been conclusively determined. In rice double mutants of $\mathrm{C}$ class genes (OSMADS3 and OSMADS58), reproductive identity was lost, a palea/carpel-like organ was observed while floral meristem (FM) became indeterminate. In addition, OsMADS3 exerted greater effects, relative to OsMADS58 (Dreni et al. 2011; Sugiyama et al. 2019; Yamaguchi et al. 2006). Knockout of $D L$ resulted in complete transformation of carpels into stamens (Yamaguchi et al. 2004). These findings show the important roles of $C$ class genes and $D L$ in carpel specify. Dysfunctions of other floral homeotic genes severely affect floral architectures, accompanied by formation of pistillodies that were transformed from other floral organs. Knockout of AP3-like B class gene (OsMADS16) led to pistil-like stamens in rice (Callens et al. 2018; Nagasawa et al. 2003). In double knock-down mutants that were deficient in PI-like B class genes (OsMADS2 and OsMADS4), pistil-like organs transformed from stamens were also observed (Callens et al. 2018; Yao et al. 2008). In a rice Tos17 insertion mutant deficient in the D class gene (OsMADS13), ovule primordia developed into carpelloid structures (Callens et al. 2018; Dreni et al. 2007; Yamaki et al. 2011). Throughout floral establishment, E class gene products function by forming higher-order protein complexes with A, B, or C class proteins (Callens et al. 2018). The AGL6-like genes work similarly to $E$ class genes (Reinheimer and Kellogg 2009; Su et al. 2019). Knockout of rice AGL6-like gene (OsMADS6) and down-regulation of TaAGL6 in wheat induced the generation of pistillodies (Ohmori et al. 2009; Su et al. 2019). Moreover, an increased number of pistils, which had been transformed from stamens, was also observed in about $52 \%$ of the flowers of the strong mutant of OsMADS32 (cfo1-1), a monocot-specific MADS-box gene, but not in its weak mutants (Hu et al. 2021; Sang et al. 2012; Wang et al. 2015). Apart from floral homeotic MADS-box genes, other genes play important roles in pistil emergence and development. In rice, dysfunctions of MFS2, FON1 and FON4 (also known as FON2) resulted in increased 
number of pistils and stamens. Compared to pistillody, additional pistils in these mutants were distinct, normal and not transformed from other floral organs (Chu et al. 2006; Li et al. 2020b; Suzaki et al. 2004; Suzaki et al. 2006; Xu et al. 2017). In wheat male-sterile mutant $d m s, 1-6$ pistils were observed along with 3 normal stamens (Duan et al. 2015).

In this study, we investigated the morphological and genetic features of tri-pistil wheat 4045 , which is a pure tri-pistil wheat line, and fine-mapped the TRP locus, the gene involved in regulation of the tri-pistil phenotype in 4045 . The tri-pistil wheat stably produced two extra late-initiated pistils, which emerged at late anther primordia (AM) stage to early tetrads (TS) stage (Feng et al. 2017), without alterations on other floral organs. Genetic analysis revealed that three grains in each 4045 floret are individually inherited while TRP penetrance varied in different $F_{1}$ populations. Segregation ratio of $F_{2}$ individuals indicated that the tri-pistil trait was controlled by a single dominant gene. Fine mapping narrowed the TRPlocus to a $\sim 97.3 \mathrm{~kb}$ region, with only two genes annotated. However, further gene sequence, functional and as well as comparative genomic analyseis rejected that the two candidate genes have been the casual genes. Furthermore, RNA-seq revealed that transcriptional abundance of floral homeotic genes that are closely associated with pistil development were significantly altered in 4045 . Our findings provide the basis for breeding as a strategy for increasing wheat yield through floral architectural modifications.

\section{Materials And Methods}

\section{Plant materials and growth conditions}

The tri-pistil wheat line, 4045, and other parental wheat lines were developed and preserved in our lab. The blue-aleurone wheat, ZLWM, was provided by Professor Yizhe He (Northwest Agriculture and Forestry University). Plant materials, including parental wheat lines, $11 \mathrm{~F}_{1}$ populations, $725 \mathrm{~F}_{2}$ individuals for fine mapping and $3494 \mathrm{~F}_{2: 3}$ plants were grown at the experimental farm of Northwest A\&F University in Yangling, Shaanxi, China during the 2014-2015, 2015-2016 and 2016-2017 wheat-growing seasons, respectively. During growth, the wheat lines were regularly watered and fertilized. Then, $101 \mathrm{~F}_{2}$ individuals for primary mapping were vernalized for 45 days at $4^{\circ} \mathrm{C}$ before being transferred to a greenhouse, where plants were grown under a photoperiod of 14-hour light:10-hour dark and temperatures between $18^{\circ} \mathrm{C}$ and $30^{\circ} \mathrm{C}$ until maturity. Plants for the two $\mathrm{F}_{3: 4}$ sub-populations were grown in a greenhouse under the same conditions without vernalization as described above, until being sampled for DNA extraction and genotyping.

\section{Tri-pistil phenotype investigation and calculation of penetrance}

To establish the tri-pistil phenotype of $4045, F_{1}$ plants from the 11 crosses and $826 F_{2}$ individuals were investigated by dissecting the florets and counting the grains inside. Two spikes for each plant (apart from those tillered on only one plantlet) were dissected floret by floret and different grain types, including 
regular grains, un-developed pistils and un-filled grains (Fig. 1d), carefully counted. Based on the observations, tri-pistils and double-pistils were considered mutant phenotypes. Penetrance was calculated as (No. of tri-pistil florets + No. of double-pistil florets) / No. of total florets $\times 100 \%$ ). Phenotypes of recombinants screened out from $\mathrm{F}_{3: 4}$ individuals were examined by visual observation of pistils at flowering stages.

\section{Optimal microscopy and Scanning electron microscopy}

Photomicrographs of floral organs and developing grains were obtained by Olympus stereo microscopy (SZX1603040112). Young spikes at different growth stages, according to Waddington et al. (1983) and Feng et al. (2017), were obtained and fixed in formaldehyde-alcohol-acetic acid (FAA), dehydrated through a standard ethanol series, and critical point dried using $\mathrm{CO}_{2}$. Dried tissues were coated with platinum and imaged by scanning electron microscopy (JSM-6360LV03040415).

\section{Genetic map construction and primary mapping}

The genomic DNA of 101 greenhouse-grown $F_{2}$ plants along with 4045 and ZLWM were extracted by the CTAB method. DNA samples were hybridized on a Wheat90K SNP array containing 81587 SNP markers by China Golden Marker (Beijing, China). Subsequently, polymorphic SNPs between 4045 and ZLWM were selected. Among them, SNPs with a missing rate higher than $5 \%$ or didn't follow the Mendelian segregation (1:2:1) were deleted. A total of 3857 eligible SNPs were randomly binned using the Bin function of IciMapping 4.1 (https://www.isbreeding.net/software/?type=detail\&id=18). Bin markers were departed into different linkage groups with a logarithm of odds (LOD) threshold score of 5.5, after which markers were ordered and the genetic map rippled with default parameters. Then, the TRP locus was identified using the Bip function of IciMapping via the inclusive composite interval mapping (ICIM) method. The genetic linkage map was drawn using the MapChart 2.3 program (https://www.wur.nl/en/show/Mapchart.htm).

\section{KASP Marker development and genotyping}

The SNPs used for KASP marker development were obtained from the Wheat 90K SNP array or detected by RNA-seq. 50 bp flanking sequences on both sides of each SNP were uploaded to a polymarker (http://www.polymarker.info/) for KASP primer designing. First, designed markers were detected by DNA samples of $42 \mathrm{~F}_{2}$ individuals along with parental, heterozygous and empty controls. Markers that could genotype the samples into 3 groups (2 parental type and 1 heterozygous type) were selected and used for genotyping.

The genomic DNA of 725 field-grown $F_{2}$ individuals, $3494 \mathrm{~F}_{2: 3}$ plants and $\mathrm{F}_{3: 4}$ plants were extracted using the CTAB method after which DNA samples were genotyped by developed KASP markers for recombinant screening. The recombinants were re-sampled and re-genotyped to confirm their genotypes.

\section{RNA-seq and bioinformatics analysis}


Total RNA of young spikes at W5.5 and W7.5 of 4045 and ZLWM were extracted using the RNAprep Pure Plant Kit (Tiangen Biotech, Beijing, China). FPKMs were calculated at BMKCloud (http://www.biocloud.net/). The two samples of 4045 were mixed and performed full-length RNA sequencing on a Pacific Biosience RS II platform. RNA-seq and full-length RNA sequencing were performed by Gene-Health Biotech (Shijiazhuang, China). Collinearity analysis was conducted by the program at Triticeae-gene Tribe (Chen et al. 2020b). Alignment of nucleic acids and protein sequences were performed using the ClustalX2 program (http://www.clustal.org/) and modified using the GeneDoc program (http://www.nrbsc.org/gfx/genedoc/). Floral homeotic MADS-box genes used for expression analyses (Supplemental Table 6) were previously identified by Schilling et al. (2020). The transcriptional expression heatmap was created by TBtools software (Chen et al. 2020a).

\section{Gene cloning}

The genomic fragment of TraesCS2D03G1038400 and its promoter region, cDNA fragment of TaMADS32-B, TraesCS2D03G1038200 and TraesCS3B03G0814800 were amplified by KOD DNA polymerase (TOYOBO, Japan) using the primers listed in Supplemental Table 7. Then, fragments were cloned into the entry vector pEASY-blunt zero cloning vector (TransGene Biotech, Beijing, China) and analyzed by Sanger sequencing.

\section{Results}

\section{Morphological characterization of the Tri-pistil wheat 4045}

To elucidate on the tri-pistil trait, spikes, especially florets in 4045, were investigated. And Zhiluowumai (ZLWM), a blue-aleurone $(\mathrm{Ba}$ ) wheat that is derived from wild blue-aleurone germplasm discovered in Qinling Mountains (China), was used as the normal single-pistil control in this study. At the late filling stage, spike length of 4045 was about $15 \mathrm{~cm}$ while its florets were stuffed to bursting due to the 2-3 grains inside (Fig. 1a). At maturity, the spikes were harvested after which 10 of them were randomly selected for further investigations. Compared to ZLWM (Fig. 1c), tri-grains of 4045 had three grains that were tightly combined (Fig. 1b). There was 1 bigger grain and 2 smaller grains (Fig. 1b, d), implying an asynchronous development for the combined grains. However, not all florets produced tri-grains. Florets of the 10 spikes were dissected and analyzed. In the investigated 460 florets, $17 \%$ (78 florets) contained 3 grains (Fig. 1d, Supplemental Table 1). However, deeper in the florets, undeveloped pistils stacked to the grains were detected. Besides, un-filled grains, which only contained seed coats without embryos or endosperms, were found in a few of the florets. These two forms of grains were considered to be aborted grains. Therefore, we further divided the florets into 6 types, that is, florets containing; i) Three grains (17\%), ii) 1 normal 2 aborted grains (42.6\%), iii) 2 normal 1 aborted grain (31.7\%), iv) 2 normal grains $(1.3 \%)$, v) 1 normal 1 aborted grain (5.4\%), and vi) 1 normal grain (2.0\%) (Fig. 1d, Supplemental Table 1). The i, ii and iii grain forms, which had been developed from three pistils, accounted for $91.3 \%$ of the florets, and were considered to exhibit tri-pistil phenotypes. The double-pistil type (iv and v) accounts for $6.7 \%$ while the single-pistil type (vi) accounts for $2 \%$ of total florets (Supplemental Table 1 ). Both tri-pistil 
and double-pistil are mutant phenotypes. Then, we calculated the penetrance of the mutant phenotype. The 10 spikes had an average penetrance of $~ 98.0 \%$, among which, the penetrance of five spikes was $100.0 \%$ with the lowest one being $92.1 \%$ (Supplemental Table 1). These findings imply that the mutant phenotype of 4045 was very stable. Notably, double-pistil florets were only present in the top two and bottom two spikelets, which developed later, relative to the middle ones. Single-pistil florets were only found in the top two spikelets. These results imply that all florets are supported to produce three pistils, and aborted pistils/grains in some of the top and bottom florets are likely to occur due to late development. Moreover, due to the aborted grains, the number of (normal) grains per spike did not reach the expected levels (Fig. 1d, Supplemental Table 1). However, the 4045 plants grown in a greenhouse under ideal conditions (like Fig. 1a, which was a spike from green-house grown plants) exhibited a much higher seed set, of which GNPS reached approximately 120 . These findings imply that the TRP trait in 4045 is sensitive to environmental conditions and that grain yield may potentially be better if ideal growth conditions are provided.

To elucidate on the floral 4045 architecture, we investigated the development processes involved in inflorescences of 4045 grains. Young spikes of 4045 and ZLWM at different growth stages were analyzed by scanning electron microscopy (SEM). At the double ridge (DR) stage, spikelet meristem (SM) emerged and started to develop (Fig. 2a, e). As it enlarged, glume primordium (GP) was initiated, this stage is hereby referred to as the glume differentiation (GD) stage (Fig. 2b, f). Then, lemma primordium (LP) and FM appeared (Fig. 2c, g). The next stage is the anther primordia (AM) stage, in which the stamen and pistil primordia emerged from FMs with visible anther primordia for some florets (Fig. 2d, h). Prior to anther primordia (AM) stage, there were no significant differences between 4045 and ZLWM (Fig. 2, a-h). However, at the tetrads (TS) stage, as young florets started to differentiate to produce immature anthers and unelongated pistils, two extra pistils were markedly observed in 4045, but not in ZLWM (Fig. 2i-I). Consistent with different sizes of three grains in one floret, the two extra pistils, which were referred to as secondary pistils (SP), were at an earlier developmental stage, compared to first differentiated pistil (primary pistil, PRP) (Fig. 2k, I). Besides, three pistils were observed in almost all of the florets, except for a few of those at the top or bottom of spikelets, in accordance with the phenomenon that double-grain and single-grain florets only appeared in the top two and bottom two spikelets of 4045 . These findings imply that differentiation of SPs stably occurred at the late AM stage to early TS and later than differentiation of PRPs. The development of the other floral organs in tri-pistil florets was completely normal.

Optical microscopy was performed to investigate 4045 pistil and grain development at heading to filling stages. In conformity with morphological features of young spikes and mature seeds, two smaller-sized extra pistils were observed in 4045, compared to normal pistils in ZLWM at heading stages, while stamens and lodicules did not exhibit any differences (Supplemental Fig. 1). Accordingly, secondary grains that had developed from SPs were smaller, relative to primary grains (Supplemental Fig. 1d-i).

Taken together, the two extra SPs, which had been initiated at late AM stage to early TS stage, were the only altered floral organs in 4045, compared to wild-type wheat (Fig. 1 and Supplemental Fig. 1). In 
addition, all floral organs, including stamens and three pistils were normal and fertile. Given that a number of aborted grains were present in the florets, the name "tri-grain" seems inaccurate, compared to "tri-pistil". Similarly, the number of entire pistils (including an ovary, two styles, and two stigmas), not the ovary, was increased and the number was always three, therefore, "multi-ovary", "multi-pistil" or "multigrain" was not the perfect name. Besides, it has not been conclusively determined whether the mutation in 4045 is allelic to the TP identified by Peng (Peng et al. 2008). Therefore, we named this phenotype in 4045, which is controlled by the TRP gene, as tri-pistil (TRP).

\section{Genetic analysis of TRP}

The three pistils in tri-pistil wheat are distinct from each other (Fig. 2, Supplemental Fig. 1). Combined to delay-developed SPs, we hypothesized that the three pistils in each floret of 4045 were independently inherited. To validate this hypothesis, we crossed 4045 with ZLWM (Fig. 1c, Supplemental Fig. 2b) and the Ba phenotype was used as an indicator to evaluate the segregation of tri-pistil wheat offsprings. Since the Ba phenotype is determined by the genotype of the sperm and two polar nuclei, segregation can be determined by the seed color of $F_{1}$ plants. As expected, grains in florets of $F_{1}$ plants exhibited different colors (Fig. 3). In some of the florets, three grains appeared in three colors (white, light blue, and dark blue), which was attributed to different numbers of $B a$ genes in fertilized polar nucleus (Fig. 3b). These findings indicate that the three pistils in each floret of 4045 independently underwent meiosis and double fertilization.

For further characterization of genetic features of TRP, 10 more wheat lines were crossed with 4045 after which 10 spikes of different $F_{1}$ plants from each cross were investigated. There were variations in penetrance of $F_{1}$ among the 11 crosses (Supplemental Table 2). Among the 10 crosses, apart from 4045 $\times$ ZLWM, penetrance was very low and in three of them, TRP was completely recessive (Supplemental Table 2). When normal wheat lines were crossed with MOV or TP, $F_{1}$ plants developed all three-pistil florets (Mahlandt et al. 2021; Peng 2003; Peng et al. 2008; Yu et al. 2020), implying that TRP may be different from MOV and TP. However, penetrance of $4045 \times Z_{L W W M ~} F_{1}(98.3 \%)$ reached the levels of the tripistil 4045 parent, suggesting that under different genomic backgrounds, the tri-pistil phenotype was suppressed to varying degrees. In $4045 \times$ ZLWM, TRP was completely dominant. Moreover, the genome of ZLWM contains genomic resources that are different from those of cultivated wheat varieties, which provides a valuable genomic background to facilitate mapping of the TRP locus. Therefore, $4045 \times$ ZLWM was chosen for further research. Based on penetrance of 4045 (Supplemental Table 1) and $F_{1}$ populations (Supplemental Table 2), $F_{2}$ individuals with penetrance rates between $0-92 \%$ were considered heterozygous. Supplemental Fig. 3 shows that the ratio of offspring phenotypes was in accordance with Mendelian segregation $\left(\chi^{2}=3.53<\chi^{2} 0.05,2=5.991\right)$, suggesting that the tri-pistil trait is controlled by a single dominant gene, consistent with findings from previous studies (Mahlandt et al. 2021; Peng 2003; Peng et al. 2008; Yu et al. 2020).

\section{Fine mapping of the TRP locus}


Although mapping studies have established that Mov-1 and Pis1 are present on chromosome 2D (Mahlandt et al. 2021; Peng et al. 2008; Yang et al. 2017; Yu et al. 2020), to date, tri-pistil loci have not

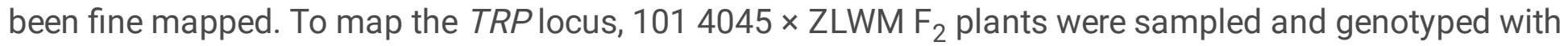
81587 SNPs on a Wheat 90K SNP array (Wang et al. 2014). Genotyping analyses revealed that the 4375 SNPs exhibited homozygous genotypes and polymorphisms between 4045 and ZLWM. After removal of SNPs that did not adhere to mendelian segregation laws, or whose missing rate was higher than $5 \%$, a total of 3857 SNPs were finally used for genetic map construction. Based on separating patterns, eligible SNPs were assigned into 1615 bins. Through linkage analysis, a high-density linkage map spanning $4564.94 \mathrm{cM}$ was constructed using the 1605 bin markers (Supplemental Table 3, Dataset 1 spreadsheet 1). To obtain accurate mapping results, two strategies were used to investigate the phenotypes of two spikes from $101 \mathrm{~F}_{2}$ individuals. The first strategy only contained three values, wild type, tri-pistil type and heterozygous, investigated by counting and classifying the florets; the second strategy involved calculation of TRP penetrance for each $F_{2}$ plant. As expected, a locus on chromosome 2D-3 between IWB29964 and IWB23687 was detected for all 4 TRP traits (Fig. 4a, Supplemental Table 4), which explains the 60.5-86.6\% phenotypic variations with LOD values from 26.6 to 44.1 (Supplemental Table 4). Given that TRP was a single dominant gene, additionally, the $5 \mathrm{~A}$ locus was only detected in one of the replicate penetrance traits (Supplemental Table 4). Thus, the 5A locus may have been a pseudo-locus, since it Mapping results were consistent with previous studies (Mahlandt et al. 2021; Yu et al. 2020).

Collinearity between the genetic map in the mapping interval and physical map (IWGSC Refseq V2.1) was not perfect (Fig. 4a, b). To verify the primary mapping result and fine-map the TRP locus, we extended the mapping interval from IWB29964-IWB23687 to IWA5206-IWB23687 and developed KASP markers for SNP IWA5206, IWB29964, IWB32175, and IWB23687 (Fig. 4a, b). The development of KASP markers for IWB32175 and IWB23687 was successful, but not for IWB29964 and IWA5206. To obtain more SNP resources and gene expressions, young spikes at Waddington5.5 (W5.5) and Waddington7.5 (W7.5) stages of 4045 and ZLWM were sampled, after which RNA-seq was performed. Using SNPs identified by RNA-seq, an SNP at 10055 bp downstream of IWA5206, located on the same gene as IWA5206, was successfully developed into a KASP marker, named IWA5206-10. Therefore, IWB23687, IWB32175, and IWA5206-10 markers were used to screen for recombinants among the $725 \mathrm{~F}_{2}$ progenies of $4045 \times$ ZLWM. A total of 42 recombinants were identified, by which the TRP locus was mapped at the interval between IWA5206-10 and IWB32175 (Fig. 4b). Subsequently, IWA5206-10 and IWB32175 were used to screen $3494 F_{2: 3}$ plants derived from heterozygous $F_{2}$ individuals, and 19 new recombinants between IWA5206-10 and IWB32175 were identified. To enrich marker densities of mapping intervals, we developed 9 additional KASP markers (Fig. 4c, Dataset 1 spreadsheet 2). A total of 23 recombinants between IWA5206-10 and IWB32175, including 4 from $F_{2}$ and 19 from $F_{2: 3}$, were genotyped with the 9 newly developed markers after which their phenotypes were investigated. Based on genotypes and phenotypes, the 23 recombinants were divided into 5 haplotypes (A-E) and mapping interval was finally narrowed to a $97.3 \mathrm{~kb}$ region, flanked by IWA5206-10 and TRP_SNP167 markers (Fig. 4c, Dataset 1 spreadsheet 2). To confirm the fine-mapping result, two recombinants from haplotype $C$ and $D$, by which the TRP locus was mapped to the IWA5206-10-TRP_SNP167 region, were selected to generate $\mathrm{F}_{3: 4}$ sub- 
populations for conformality. The $\mathrm{F}_{3: 4}$ individuals were genotyped with two flanking markers. As expected, segregation was detected for IWA5206 (heterozygous in $F_{2: 3}$ generation) in both $F_{3: 4}$ subpopulations, however, it was not detected for TRP_SNP167 (homozygous in $\mathrm{F}_{2: 3}$ generation) (Supplemental Table 5), confirming the authenticity and accuracy of the fine-mapping result.

\section{Analysis of candidate genes in the mapping interval}

Only two genes, TraesCS2D03G1038200 harboring IWA5206-10 and TraesCS2D03G1038400 harboring TRP_SNP167 (Supplemental Fig. 5b, c), were annotated in the genome reference of Chinese Spring (CS), IWGSC Refseq V2.1 (Zhu et al. 2021), within the mapping interval (Fig. 5). Based on transposable elements (TEs) annotation of the CS genome, TEs accounted for about $75 \%$ of the mapping region (Fig. 5a). To obtain more information about this mapping region, we analyzed the collinearity between the 11 available wheat genomes along with genomes of Aegilops tauschii (D genome) and Thinopyrum elongatum (E genome) (Fig. 5b). The mapping region in the 11 wheat genomes was divided into two haplotypes ( $97 \mathrm{~kb}$ type and $\sim 324 \mathrm{~kb}$ type), however, no extra genes were annotated (Fig. 5b). In the $A$. tauschii genome (Aet V4.0), at $103.5 \mathrm{~kb}$ downstream of the TraesCS2D03G1038200 homolog, a singleexon gene (AET2GV21024800) encoding an unknown protein was annotated (Fig. 5, Supplemental Fig. 4a). However, its structure is atypical with the absence of start and stop codons (Supplemental Fig. 4a). Since AET2Gv21024800 has been annotated as a high-confidence class gene (Luo et al. 2017), we aligned its coding sequence (CDS) and protein sequences to CS databases. Seven proteins exhibited a high identity (>80\%) with AET2Gv21024800 (Supplemental Fig. 4b), consistent with CDS alignment to the CS high-confidence CDS database (Dataset 1 spreadsheet 3). In contrast, alignment to CS low-confidence CDS database detected 381 hits (Dataset 1 spreadsheet 4). Since AET2Gv21024800 showed high similarity to only a part of 4 out of 4 wheat proteins, these findings imply that AET2GV21024800 might be a non-functional pseudogene. To elucidate on the 4045 transcriptome, we mixed the RNA of young spikes at W5.5 and W7.5 of 4045, after which we performed full-length RNA-seq (Pacbio). Therefore, the CDS of AET2Gv21024800 was aligned to full-length transcript library, however, no hit was detected. Consistently, expressions of the 7 wheat homologs was not detected in RNA-seq (Supplemental Fig. 4c). These findings imply that $A E T 2 G V 21024800$ is not the TRP candidate.

Thereafter, we evaluated two flanking genes of the mapping region. Transcriptional analysis by RNA-seq and structure analyses were performed. TraesCS2D03G1038200, which consists of 28 exons (Supplemental Fig. 5b), encodes an ATP binding cassette C member 2 (ABCC2) transporter family protein. Transcriptional differences of TraesCS2D03G1038200 and its homologs in A and B sub-genomes between 4045 and ZLWM were not significant (Supplemental Fig. 5a). Six SNPs were detected in the encoding region, however, none of them resulted in amino acid alterations (Supplemental Fig. 5b). ABCC2 is involved in defense molecule accumulation, heavy metal transport, tolerance to biotic and abiotic stresses, as well as transport of other metabolites in plant species such as Arabidopsis and saffron. However, it has not been conclusively determined whether ABCC2 or members of the ABC transporter family contribute to flower architecture development (Behrens et al. 2019; Dahuja et al. 2021; Demurtas et al. 2019; Do et al. 2021; Park et al. 2012). 
The expression of TraesCS2D03G1038400 was markedly elevated in the two samples of 4045, especially at the W7.5 stage (Supplemental Fig. 5a). Compared to the CS sequence, an SNP, C138T, was detected at codon 46 (Supplemental Fig. 5c) in 4045, however, it was not associated with any amino acid alteration. Moreover, a single nucleotide insertion was detected at 535-bp upstream of the start codon, which might have led to increased transcriptional abundance. TraesCS2D03G1038400 encodes a remorin family protein. Moreover, it has a 75.6\% identity with its rice homolog, OsGSD1 (Os04g0620200) (Supplemental Fig. 5d). Enhanced expression of OSGSD1 was associated with reduced grain setting, carbohydrate accumulation in leaves, and lower soluble sugar contents in phloem exudates of rice gsd1-D activation mutant. Any abnormalities in the stamen and pistil of $g s d 1-D$ were not detected (Gui et al. 2014). As a plant-specific protein family, the significance of remorin family proteins in plant floral establishment has not been established (Gouguet et al. 2021).

In addition to structure and expression analysis of the two flanking genes, a recent study reported that there were no significant differences at protein levels for both TraesCS2D03G1038200 and TraesCS2D03G1038400 between tri-pistil and normal wheat (Li et al. 2020c).

These results imply that TraesCS2D03G1038200 and TraesCS2D03G1038400 are not TRP candidates. Tri-pistil wheat, including 4045, may carry a new haplotype that is different from normal wheat (Fig. 5) with a gain-of-function mutation in the mapping region, leading to generation of the tri-pistil phenotype.

\section{Transcriptional analysis of floral homeotic genes in $\mathbf{4 0 4 5}$}

Floral homeotic genes play vital roles in floral establishment. Altered expressions of these genes are associated with abnormalities in floral organs. To investigate the relationship between TRP and floral homeotic genes, their expressions were analyzed by RNA-seq of young spikes at W5.5 and W7.5 stages. At the W5.5 stage, pistil differentiation in normal wheat is considered complete (Fig. 2i, j) (Waddington et al. 1983). However, in 4045, PRPs finished the differentiation while the late-developed SPs were still at stage W4.5-W5.5 (Fig. 2k, I). Therefore, differences in expressions of pistil/carpel formation-related genes between 4045 and ZLWM were supposed to be detected at W5.5. At the W7.5 stage, both PRPs and SPs completed pistil differentiation. For some genes, different expression patterns were detected in different sub-genomes (Fig. 6). Since orthologs in wheat sub-genomes usually exhibit high similarities and share redundant functions, we analyzed the total expressions of these ortholog genes without normalization (Supplemental Fig. 6). Levels of TaAG-A2 and TaAG-B2 in 4045 at W5.5 were significantly elevated, however, the increase in TaAG-D2 levels was not significant. These differences were not detected at W7.5 (Fig. 6). TaAG-2s are orthologs of rice OsMADS3, which is transiently expressed during the initiation stages of stamen, carpel and ovule primordia (Yamaguchi et al. 2006). Therefore, upregulation of TaAG$2 s$ indicated that they exerted their functions at W5.5 and contributed to SPs formation when PRPs had finished differentiating. Moreover, overexpressions of OSMADS3 did not result in alterations of pistils (Kyozuka and Shimamoto 2002), suggesting that TaAG-2s may be involved in TRP-regulation, rather than directly determine SPs formation. However, at both stages, significant differences in $T a D L s$, an important pistil determinator, were not detected (Fig. 6). Although down-regulated expressions for TaDL-A and TaDL$B$ were detected in 4045 , they were largely supplemented by TaDL-D (Supplemental Fig. 6). B class 
TaAP3-1s and D class TaSTK-1s, rice OsMADS16 and OSMADS13 orthologs, respectively, were downregulated in 4045 (Fig. 6). During ovule development, OsMADS13 acts as a repressor of the carpel pathway (Osnato et al. 2021). On this account, the decrease in TaSTK-1s may moderate the suppression of carpel development and facilitate SPs formation. A possible reason for downregulation of TaAP3-1s is that it might be directly/indirectly regulated by TRP. Furthermore, several TaSEP1s were differentially expressed between 4045 and ZLWM (Fig. 6), however, their total expressions were complemented by other homologs (Supplemental Fig. 6). TaMADS32-B1 was downregulated 5-6 fold in 4045 at both stages (Fig. 6), whereas total expressions were comparable (Supplemental Fig. 6). Its encoding sequence was analyzed and no alterations were found, indicating that the functions of TaMADS32s were not significantly affected in 4045 .

\section{Discussion}

Floral organ development influences grain yields of cereal crops, including wheat (Williams and Sorrells 2014). Male floral organs of wheat produce large amounts of pollen whereas only one pistil harbors one ovule in each floret per spike. On this account, abnormalities in pistils have significant effects on wheat yields. Such abnormalities or variations provide non-substitutable resources for understanding floral architectures and increase the yields. A series of anomalous-developed-pistil mutants have been identified, which have helped elucidate on molecular mechanisms involved in pistil establishment. Based on previous studies, we divided anomalous-developed-pistil mutants into three types: pistillody type, indefinite-floral-organ-number-increase (IFONI) type and accurately-regulated-pistil-number-increase (ARPNI) type (Fig. 7). The classical flower development ABCDE model (Fig. 7a) has been well-investigated in monocot crops, especially in rice (Callens et al. 2018; Li et al. 2021; Reinheimer and Kellogg 2009; Zhao et al. 2006). Silencing or down-regulation of AP3-like (B class), PI-like (B class), AG-like (D class), AGL6like or monocot specific MADS32 led to generation of pistillodies, which were transformed from stamens, lodicule or even ovules (Dreni et al. 2007; Nagasawa et al. 2003; Ohmori et al. 2009; Reinheimer and Kellogg 2009; Su et al. 2019; Yamaki et al. 2011; Yao et al. 2008) (Fig. 7b). In pistillody type mutants, additional pistils or pistil-like structures were found to be partly fertile, and accompanied by dysfunctions of other floral organs, resulting in decreased grain yields (Callens et al. 2018; Dreni et al. 2007; Nagasawa et al. 2003; Ohmori et al. 2009; Reinheimer and Kellogg 2009; Su et al. 2019; Yamaki et al. 2011; Yao et al. 2008). Apart from pistillodies, another type of pistil development mutant has been identified. In mutants such as fon 1-2, fon $4 s, m s f 2$ in rice and dms in wheat, an indefinite number of extra normally developed pistils were generated (Fig. 7c) (Chu et al. 2006; Duan et al. 2015; Li et al. 2020b; Suzaki et al. 2004; Suzaki et al. 2006; Xu et al. 2017). In contrast, tri-pistil wheat normally produced all floral organs, except for the generation of a fixed number (three) of pistils (Fig. 2, Supplemental Fig. 1). Apart from delayed emergence and development, SPs were normal, fertile, and capable of producing grains, thereby increasing grain numbers (Fig. 1A, Fig. 2, Supplemental Fig. 1 and Supplemental Table 1). Based on the characteristics of tri-pistil wheat, we defined this pistil mutant type as precisely-regulated-pistil-numberincrease (PRPNI) type. PRPNI mutants provide a novel resource for exploration of floral development and open opportunities for manipulation strategies to increase crop yields. 
Studies have aimed at identifying the causal gene(s) of tri-pistil wheat. It has been postulated that the causal gene is located on 2DL (Mahlandt et al. 2021; Peng et al. 2008; Wang et al. 2009; Yang et al. 2017; Yu et al. 2020; Zhu et al. 2019). Using multiple molecular marker systems, Yu et al. (2020) mapped the Pis1-2020 locus to the 7.32 Mb region of 2DL (Supplemental Fig. 7). Subsequently, Mahlandt et al. (2021) physically located Mov-1 to a $1.1 \mathrm{Mb}$ region by combining radiation hybrid (RH) and recombination-based mapping approaches (Supplemental Fig. 7). However, the locus has not yet been fine-mapped. In this study, using a total of 4320 progenies of $4045 \times$ ZLWM, we narrowed the mapping region down to a $97.3 \mathrm{~kb}$ interval (Fig. 4, Supplemental Fig. 7). To obtain a robust result, genotypes of all recombinants were double examined and the final mapping result validated using $F_{3: 4}$ sub-populations (Supplemental Table 3). Pursuant to comparisons of recent mapping results, all tri-pistil loci were placed on an approximately $30 \mathrm{Mb}$ region of chromosome 2DL (Supplemental Fig. 7). However, due to different origins of materials, it is challenging to establish if TRP is allelic to Pis 1 or Mov-1 due (Mahlandt et al. 2021; Yu et al. 2020). In addition, poor penetrance of most $4045 F_{1}$ populations, which differed from previous studies, implied that TRP may be different from Pis 1 or Mov-1.

Map-based cloning is an important strategy for gene identification in wheat, whereas it was difficult and time-consuming before the release of wheat genomes. Even though the wheat genome is constantly being updated, in some cases, target genes are absent in reference genomes. Wheat Fusarium head blight 1 (Fhb1) was cloned by screening bacterial artificial chromosome (BAC) libraries of Sumai 3 (Rawat et al. 2016), after which Fhb7 was identified by de novo-assembly of Thinopyrum elongatum genome (Wang et al. 2020). Moreover, reference genomes lack the Powdery mildew 41 (Pm41), which was discovered by screening the BAC library of wild emmer wheat accession IW2 (Li et al. 2020a). Based on available wheat genome assemblies, only two flanking genes within the TRP mapping region were annotated (Fig. 5). Along with an extra gene annotated in A. tauschii genome, three genes were considered potential candidate genes. Nevertheless, through gene structure and expression analysis, previous studies provided sufficient evidence for rejecting the hypothesis that the three genes are casual genes of TRP (Supplemental Fig. 4, Supplemental Fig. 5). These analyses suggested that the tri-pistil phenotype may be caused by a gain-of-function gene that does not exist in reference wheat genomes. Furthermore, we discussed that the PRPNI type mutant is novel germplasm (Fig. 7). To date, PRPNI type mutations have not been reported in other plant species, including rice and Arabidopsis, implying that TRP might be controlled by a wheat or Triticum specific gene, furtherly reducing the possibility that the two flanking genes are causal genes.

Pistils in wheat and many other grass species are derived from three fused carpel primordia(Dreni et al. 2013; Kellogg 2001; Rudall et al. 2005; Shen et al. 2021). Therefore, it is important to determine if the initial three carpel primordia develop into three intact pistils in tri-pistil wheat by facilitation of TRP. Moreover, regulatory mechanisms involved in pistil development from the three primordia have not been established. A recent review elucidated on a reasonable model for rice carpel development (Shen et al. 2021), based on which we proposed a model for specifications of PRPNI pistils (Fig. 7d). Briefly, TaDLs and C Class genes specify pistil formation. E class genes in combination with TaAGL6s positively 
regulate $\mathrm{C}$ class genes by forming heterodimers with them. A class genes and $\mathrm{C}$ class genes, $\mathrm{B}$ class genes and $T a D L s$, antagonistically regulate the expressions of each other. TaSTK-1s, D class genes that specify the identity of ovules, are also involved in pistil development, even though their expressions are restricted to ovules (Callens et al. 2018; Shen et al. 2021). The TRP regulates the pistil development in an unknown way and leads to the formation of PRPNI pistils. The PRPNI provides a novel direction to investigate wheat floral organ development. Investigation of the regulatory mechanisms of TRP will elucidate on the processes and pathways involved in pistil development.

GNPS is a key component of wheat grain yield. To improve GNPS, special germplasms with high GNPS were investigated. For instance, introgression or translocation of Agropyron cristatum 6P chromosome into common wheat significantly increases GNPS to 120 (Wu et al. 2006; Zhang et al. 2016). This germplasm has been successfully utilized in breeding of Pubing series wheat cultivars. The null mutation of WFZP-A along with deletion of WFZP-D led to development of a triple spikelet (TRS) phenotype and increased the GNPS (Du et al. 2021). Similarly, the tri-pistil wheat, 4045, also produces high GNPS (Fig. 1a, Supplemental Table 1). In addition, our unpublished data showed that kernel weight of $4 F_{1}$ populations increased more than 2 folds, compared to the normal parental wheat line, which was also found by Mahlandt et al. (2021). These observations imply the enormous potential of TRP in enhancing yields and development of wheat hybrid-breeding. Therefore, investigation of tri-pistil wheat is of great interest for basic research on floral developments and applications on crop yield increases. We systematically investigated the morphologic features of TRP and fine-mapped the TRP locus, thereby opening opportunities to understand and utilize the excellent germplasm.

\section{Declarations}

Acknowledgements This research was supported by Program of Introducing Talents of Innovative Discipline to Universities (Project 111) from the State Administration of Foreign Experts Affairs (B18042) and Key R \& D Program of Shaanxi Province (2018NY-056).

Author contribution statement Conceptualization, Z.W., T.L. and X.S.; methodology, T.L., C.L. and W.J.; software, T.L., C.L., W.J. and Y.S.; validation, T.L.; formal analysis, T.L., H.W., E.X. and Y.W.; investigation, T.L., Q.J. and C.M.; resources, E.X. and Z.W.; data curation, T.L.; writing-original draft preparation, T.L.; writing-review and editing, T.L. and Y.S.; visualization, T.L.; supervision, Z.W. and X.S.; funding acquisition, Z.W. and Z.K..

Data availability The RNA-seq reads have been deposited into GenBank under BioProject PRJNA771461. The full-length transcriptic reads have been deposited into GenBank under BioProject PRJNA786660.

Conflict of interest The authors declared that there is no confict of interest.

\section{References}


1. Asseng S, Guarin JR, Raman M, Monje O, Kiss G, Despommier DD, Meggers FM, Gauthier PP (2020) Wheat yield potential in controlled-environment vertical farms. Proc Natl Acad Sci 117:19131-19135

2. Behrens CE, Smith KE, lancu CV, Choe J-y, Dean JV (2019) Transport of anthocyanins and other flavonoids by the Arabidopsis ATP-binding cassette transporter AtABCC2. Sci Rep 9:1-15

3. Calderini DF, Castillo FM, Arenas MA, Molero G, Reynolds MP, Craze M, Bowden S, Milner MJ, Wallington EJ, Dowle A, Gomez LD, McQueen-Mason SJ (2021) Overcoming the trade-off between grain weight and number in wheat by the ectopic expression of expansin in developing seeds leads to increased yield potential. New Phytol 230:629-640. https://doi.org/10.1111/nph.17048

4. Callens C, Tucker MR, Zhang D, Wilson ZA (2018) Dissecting the role of MADS-box genes in monocot floral development and diversity. J Exp Bot 69:2435-2459. https://doi.org/10.1093/jxb/ery086

5. Chen C, Chen H, Zhang Y, Thomas HR, Frank MH, He Y, Xia R (2020a) TBtools: an integrative toolkit developed for interactive analyses of big biological data. Mol Plant 13:1194-1202

6. Chen J, Zhang L, Wu B (1983) A preliminary report on the discovery and breeding of the "tri-grain wheat". Acta Agronomica Sinica 9:69-71

7. Chen W, Liu W, Lei Q (1999) Comparative study of peroxidase isozyme and proteins of trigrain and common wheat in seedlings. Acta Agronomica Sinica 25:650-653

8. Chen Y, Song W, Xie X, Wang Z, Guan P, Peng H, Jiao Y, Ni Z, Sun Q, Guo W (2020b) A CollinearityIncorporating Homology Inference Strategy for Connecting Emerging Assemblies in the Triticeae Tribe as a Pilot Practice in the Plant Pangenomic Era. Mol Plant 13:1694-1708. https://doi.org/10.1016/j.molp.2020.09.019

9. Chu H, Qian Q, Liang W, Yin C, Tan H, Yao X, Yuan Z, Yang J, Huang H, Luo D (2006) The floral organ number4 gene encoding a putative ortholog of Arabidopsis CLAVATA3 regulates apical meristem size in rice. Plant Physiol 142:1039-1052

10. Dahuja A, Kumar RR, Sakhare A, Watts A, Singh B, Goswami S, Sachdev A, Praveen S (2021) Role of ATP-binding cassette transporters in maintaining plant homeostasis under abiotic and biotic stresses. Physiol Plant 171:785-801. https://doi.org/10.1111/ppl.13302

11. Demurtas OC, de Brito Francisco R, Diretto G, Ferrante P, Frusciante S, Pietrella M, Aprea G, Borghi L, Feeney M, Frigerio L (2019) ABCC transporters mediate the vacuolar accumulation of crocins in saffron stigmas. Plant Cell 31:2789-2804

12. Do THT, Martinoia E, Lee Y, Hwang J-U (2021) 2021 update on ATP-binding cassette (ABC) transporters: how they meet the needs of plants. Plant Physiol 187:1876-1892. https://doi.org/10.1093/plphys/kiab193

13. Dreni L, Jacchia S, Fornara F, Fornari M, Ouwerkerk PBF, An G, Colombo L, Kater MM (2007) The Dlineage MADS-box gene OsMADS13 controls ovule identity in rice. Plant J 52:690-699. https://doi.org/10.1111/j.1365-313X.2007.03272.x

14. Dreni L, Osnato M, Kater MM (2013) The ins and outs of the rice AGAMOUS subfamily. Mol Plant 6:650-664. https://doi.org/10.1093/mp/sst019 
15. Dreni L, Pilatone A, Yun D, Erreni S, Pajoro A, Caporali E, Zhang D, Kater MM (2011) Functional analysis of all AGAMOUS subfamily members in rice reveals their roles in reproductive organ identity determination and meristem determinacy. Plant Cell 23:2850-2863.

https://doi.org/10.1105/tpc. 111.087007

16. Du D, Zhang D, Yuan J, Feng M, Li Z, Wang Z, Zhang Z, Li X, Ke W, Li R, Chen Z, Chai L, Hu Z, Guo W, Xing J, Su Z, Peng H, Xin M, Yao Y, Sun Q, Liu J, Ni Z (2021) FRIZZY PANICLE defines a regulatory hub for simultaneously controlling spikelet formation and awn elongation in bread wheat. New Phytol 231:814-833. https://doi.org/10.1111/nph.17388

17. Duan Z, Shen C, Li Q, LÜ G, Ni Y, Yu D, Niu J (2015) Identification of a novel male sterile wheat mutant dms conferring dwarf status and multi-pistils. Journal of Integrative Agriculture 14:17061714. https://doi.org/10.1016/s2095-3119(14)60936-9

18. Feng N, Song G, Guan J, Chen K, Jia M, Huang D, Wu J, Zhang L, Kong X, Geng S, Liu J, Li A, Mao L (2017) Transcriptome Profiling of Wheat Inflorescence Development from Spikelet Initiation to Floral Patterning Identified Stage-Specific Regulatory Genes. Plant Physiol 174:1779-1794. https://doi.org/10.1104/pp.17.00310

19. Foulkes MJ, Slafer GA, Davies WJ, Berry PM, Sylvester-Bradley R, Martre P, Calderini DF, Griffiths S, Reynolds MP (2011) Raising yield potential of wheat. Ill. Optimizing partitioning to grain while maintaining lodging resistance. J Exp Bot 62:469-486

20. Gouguet P, Gronnier J, Legrand A, Perraki A, Jolivet M-D, Deroubaix A-F, German-Retana S, Boudsocq M, Habenstein B, Mongrand S, Germain V (2021) Connecting the dots: from nanodomains to physiological functions of REMORINs. Plant Physiol 185:632-649.

https://doi.org/10.1093/plphys/kiaa063

21. Gui J, Liu C, Shen J, Li L (2014) Grain setting defect1, Encoding a Remorin Protein, Affects the Grain Setting in Rice through Regulating Plasmodesmatal Conductance. Plant Physiol 166:1463-1478. https://doi.org/10.1104/pp.114.246769

22. Guo J, Zhang G, Song Y, Ma S, Niu N, Wang J (2019) Comparative transcriptome profiling of multiovary wheat under heterogeneous cytoplasm suppression. Sci Rep 9:8301.

https://doi.org/10.1038/s41598-019-43277-5

23. Hu Y, Wang L, Jia R, Liang W, Zhang X, Xu J, Chen X, Lu D, Chen M, Luo Z, Xie J, Cao L, Xu B, Yu Y, Persson S, Zhang D, Yuan Z (2021) Rice transcription factor MADS32 regulates floral patterning through interactions with multiple floral homeotic genes. J Exp Bot 72:2434-2449. https://doi.org/10.1093/jxb/eraa588

24. Ito T (2019) Functional Dissection of Class C Genes in Rice. Plant Cell Physiol 60:1164-1165. https://doi.org/10.1093/pcp/pcz093

25. Kellogg EA (2001) Evolutionary history of the grasses. Plant Physiol 125:1198-1205

26. Kyozuka J, Shimamoto K (2002) Ectopic expression of OsMADS3, a rice ortholog of AGAMOUS, caused a homeotic transformation of lodicules to stamens in transgenic rice plants. Plant Cell Physiol 43:130-135 
27. Li G, Kuijer HNJ, Yang X, Liu H, Shen C, Shi J, Betts N, Tucker MR, Liang W, Waugh R, Burton RA, Zhang D (2021) MADS1 maintains barley spike morphology at high ambient temperatures. Nature Plants 7:1093-1107. https://doi.org/10.1038/s41477-021-00957-3

28. Li M, Dong L, Li B, Wang Z, Xie J, Qiu D, Li Y, Shi W, Yang L, Wu Q, Chen Y, Lu P, Guo G, Zhang H, Zhang P, Zhu K, Li Y, Zhang Y, Wang R, Yuan C, Liu W, Yu D, Luo MC, Fahima T, Nevo E, Li H, Liu Z (2020a) A CNL protein in wild emmer wheat confers powdery mildew resistance. New Phytol 228:1027-1037. https://doi.org/10.1111/nph.16761

29. Li YF, Zeng XQ, Li Y, Wang L, Zhuang H, Wang Y, Tang J, Wang HL, Xiong M, Yang FY, Yuan XZ, He GH (2020b) MULTI-FLORET SPIKELET 2, a MYB Transcription Factor, Determines Spikelet Meristem Fate and Floral Organ Identity in Rice. Plant Physiol 184:988-1003. https://doi.org/10.1104/pp.20.00743

30. Li Z, Ma S, Liu D, Zhang L, Du X, Xia Y, Song Q, Li Y, Zhang Y, Li Z, Yang Z, Niu N, Wang J, Song Y, Zhang $G$ (2020c) Morphological and proteomic analysis of young spikes reveals new insights into the formation of multiple-pistil wheat. Plant Sci 296:110503. https://doi.org/10.1016/j.plantsci.2020.110503

31. Luo MC, Gu YQ, Puiu D, Wang H, Twardziok SO, Deal KR, Huo N, Zhu T, Wang L, Wang Y, McGuire PE, Liu S, Long H, Ramasamy RK, Rodriguez JC, Van SL, Yuan L, Wang Z, Xia Z, Xiao L, Anderson OD, Ouyang S, Liang Y, Zimin AV, Pertea G, Qi P, Bennetzen JL, Dai X, Dawson MW, Muller HG, Kugler K, Rivarola-Duarte L, Spannagl M, Mayer KFX, Lu FH, Bevan MW, Leroy P, Li P, You FM, Sun Q, Liu Z, Lyons E, Wicker T, Salzberg SL, Devos KM, Dvorak J (2017) Genome sequence of the progenitor of the wheat D genome Aegilops tauschii. Nature 551:498-502. https://doi.org/10.1038/nature24486

32. Mahlandt A, Rawat N, Leonard J, Venglat P, Datla R, Meier N, Gill BS, Riera-Lizarazu O, Coleman G, Murphy AS, Tiwari VK (2021) High-resolution mapping of the Mov-1 locus in wheat by combining radiation hybrid $(\mathrm{RH})$ and recombination-based mapping approaches. Theor Appl Genet 134:23032314. https://doi.org/10.1007/s00122-021-03827-w

33. Molero G, Joynson R, Pinera-Chavez FJ, Gardiner LJ, Rivera-Amado C, Hall A, Reynolds MP (2019) Elucidating the genetic basis of biomass accumulation and radiation use efficiency in spring wheat and its role in yield potential. Plant Biotechnol J 17:1276-1288. https://doi.org/10.1111/pbi.13052

34. Nagasawa N, Miyoshi M, Sano Y, Satoh H, Hirano H, Sakai H, Nagato Y (2003) SUPERWOMAN1 and DROOPING LEAF genes control floral organ identity in rice. Development 130:705-718. https://doi.org/10.1242/dev.00294

35. Ohmori S, Kimizu M, Sugita M, Miyao A, Hirochika H, Uchida E, Nagato Y, Yoshida H (2009) MOSAIC FLORAL ORGANS1, an AGL6-like MADS box gene, regulates floral organ identity and meristem fate in rice. Plant Cell 21:3008-3025

36. Osnato M, Lacchini E, Pilatone A, Dreni L, Grioni A, Chiara M, Horner D, Pelaz S, Kater MM (2021) Transcriptome analysis reveals rice MADS13 as an important repressor of the carpel development pathway in ovules. J Exp Bot 72:398-414. https://doi.org/10.1093/jxb/eraa460

37. Park J, Song WY, Ko D, Eom Y, Hansen TH, Schiller M, Lee TG, Martinoia E, Lee Y (2012) The phytochelatin transporters $A t A B C C 1$ and $A t A B C C 2$ mediate tolerance to cadmium and mercury. Plant 
J 69:278-288

38. Peng Z (2003) A new mutation in wheat producing three pistils in a floret. J Agron Crop Sci 189:270272

39. Peng Z, Martinek P, Kosuge K, Kuboyama T, Watanabe N (2008) Genetic mapping of a mutant gene producing three pistils per floret in common wheat. J Appl Genet 49:135-139

40. Peng Z, Yang J, Wei S, Zeng J (2004) Characterization of the common wheat (Triticum aestivum L.) mutation line producing three pistils in a floret. Hereditas 141:15-18

41. Rawat N, Pumphrey MO, Liu S, Zhang X, Tiwari VK, Ando K, Trick HN, Bockus WW, Akhunov E, Anderson JA, Gill BS (2016) Wheat Fhb1 encodes a chimeric lectin with agglutinin domains and a pore-forming toxin-like domain conferring resistance to Fusarium head blight. Nat Genet 48:15761580. https://doi.org/10.1038/ng.3706

42. Reinheimer R, Kellogg EA (2009) Evolution of AGL6-like MADS box genes in grasses (Poaceae): ovule expression is ancient and palea expression is new. Plant Cell 21:2591-2605

43. Rudall PJ, Stuppy W, Cunniff J, Kellogg EA, Briggs BG (2005) Evolution of reproductive structures in grasses (Poaceae) inferred by sister-group comparison with their putative closest living relatives, Ecdeiocoleaceae. Am J Bot 92:1432-1443

44. Sang X, Li Y, Luo Z, Ren D, Fang L, Wang N, Zhao F, Ling Y, Yang Z, Liu Y, He G (2012) CHIMERIC FLORAL ORGANS1, encoding a monocot-specific MADS box protein, regulates floral organ identity in rice. Plant Physiol 160:788-807. https://doi.org/10.1104/pp.112.200980

45. Schilling S, Kennedy A, Pan S, Jermiin LS, Melzer R (2020) Genome-wide analysis of MIKC-type MADS-box genes in wheat: pervasive duplications, functional conservation and putative neofunctionalization. New Phytol 225:511-529. https://doi.org/10.1111/nph.16122

46. Shen C, Li G, Dreni L, Zhang D (2021) Molecular Control of Carpel Development in the Grass Family. Front Plant Sci 12:635500. https://doi.org/10.3389/fpls.2021.635500

47. Su Y, Liu J, Liang W, Dou Y, Fu R, Li W, Feng C, Gao C, Zhang D, Kang Z, Li H (2019) Wheat AGAMOUS LIKE 6 transcription factors function in stamen development by regulating the expression of Ta APETALA3. Development. 146https://doi.org/10.1242/dev.177527

48. Sugiyama SH, Yasui Y, Ohmori S, Tanaka W, Hirano HY (2019) Rice Flower Development Revisited: Regulation of Carpel Specification and Flower Meristem Determinacy. Plant Cell Physiol 60:12841295. https://doi.org/10.1093/pcp/pcz020

49. Suzaki T, Sato M, Ashikari M, Miyoshi M, Nagato Y, Hirano HY (2004) The gene FLORAL ORGAN NUMBER1 regulates floral meristem size in rice and encodes a leucine-rich repeat receptor kinase orthologous to Arabidopsis CLAVATA1. Development 131:5649-5657. https://doi.org/10.1242/dev.01441

50. Suzaki T, Toriba T, Fujimoto M, Tsutsumi N, Kitano H, Hirano HY (2006) Conservation and diversification of meristem maintenance mechanism in Oryza sativa: Function of the FLORAL ORGAN NUMBER2 gene. Plant Cell Physiol 47:1591-1602. https://doi.org/10.1093/pcp/pcl025 
51. Theißen G (2001) Development of floral organ identity: stories from the MADS house. Curr Opin Plant Biol 4:75-85

52. Waddington SR, Cartwright PM, Wall PC (1983) A Quantitative Scale of Spike Initial and Pistil Development in Barley and Wheat. Ann Botany 51:119-130. https://doi.org/10.1093/oxfordjournals.aob.a086434

53. Wang H, Sun S, Ge W, Zhao L, Hou B, Wang K, Lyu Z, Chen L, Xu S, Guo J, Li M, Su P, Li X, Wang G, Bo C, Fang X, Zhuang W, Cheng X, Wu J, Dong L, Chen W, Li W, Xiao G, Zhao J, Hao Y, Xu Y, Gao Y, Liu W, Liu Y, Yin H, Li J, Li X, Zhao Y, Wang X, Ni F, Ma X, Li A, Xu SS, Bai G, Nevo E, Gao C, Ohm H, Kong L (2020) Horizontal gene transfer of Fhb7 from fungus underlies Fusarium head blight resistance in wheat. Science. 368https://doi.org/10.1126/science.aba5435

54. Wang H, Zhang L, Cai Q, Hu Y, Jin Z, Zhao X, Fan W, Huang Q, Luo Z, Chen M, Zhang D, Yuan Z (2015) OsMADS32 interacts with PI-like proteins and regulates rice flower development. J Integr Plant Biol 57:504-513. https://doi.org/10.1111/jipb.12248

55. Wang J, Zhang G, Liu H (2005) Detection of a RAPD Marker Linked to Dominant Multi-ovary Gene in Wheat(Triticum aestivum). Journal of Agricultural Biotechnology 13:553-556

56. Wang S, Wong D, Forrest K, Allen A, Chao S, Huang BE, Maccaferri M, Salvi S, Milner SG, Cattivelli L, Mastrangelo AM, Whan A, Stephen S, Barker G, Wieseke R, Plieske J, International Wheat Genome, Sequencing C, Lillemo M, Mather D, Appels R, Dolferus R, Brown-Guedira G, Korol A, Akhunova AR, Feuillet C, Salse J, Morgante M, Pozniak C, Luo MC, Dvorak J, Morell M, Dubcovsky J, Ganal M, Tuberosa R, Lawley C, Mikoulitch I, Cavanagh C, Edwards KJ, Hayden M, Akhunov E (2014) Characterization of polyploid wheat genomic diversity using a high-density 90,000 single nucleotide polymorphism array. Plant Biotechnol J 12:787-796. https://doi.org/10.1111/pbi.12183

57. Wang Y, Ding H, Chen J (1990) Differentiation of additional pistils in a trigrain wheat. Journal of Lanzhou University (Natural Science) 26:80-84

58. Wang Z, Xu D, Ji J, Wang J, Wang M, Ling H, Sun G, Li J (2009) Genetic analysis and molecular markers associated with multi-gynoecia (Mg) gene in Trigrain whea. Can J Plant Sci 89:845-850

59. Williams K, Sorrells ME (2014) Three-dimensional seed size and shape QTL in hexaploid wheat (Triticum aestivum L.) populations. Crop Sci 54:98-110

60. Wu J, Yang X, Wang H, Li H, Li L, Li X, Liu W (2006) The introgression of chromosome 6P specifying for increased numbers of florets and kernels from Agropyron cristatum into wheat. Theor Appl Genet 114:13-20. https://doi.org/10.1007/s00122-006-0405-0

61. Xu W, Tao J, Chen M, Dreni L, Luo Z, Hu Y, Liang W, Zhang D (2017) Interactions between FLORAL ORGAN NUMBER4 and floral homeotic genes in regulating rice flower development. J Exp Bot 68:483-498. https://doi.org/10.1093/jxb/erw459

62. Yamaguchi T, Lee DY, Miyao A, Hirochika H, An G, Hirano HY (2006) Functional diversification of the two C-class MADS box genes OSMADS3 and OSMADS58 in Oryza sativa. Plant Cell 18:15-28. https://doi.org/10.1105/tpc.105.037200 
63. Yamaguchi T, Nagasawa N, Kawasaki S, Matsuoka M, Nagato Y, Hirano HY (2004) The YABBY gene DROOPING LEAF regulates carpel specification and midrib development in Oryza sativa. Plant Cell 16:500-509. https://doi.org/10.1105/tpc.018044

64. Yamaki S, Nagato Y, Kurata N, Nonomura K (2011) Ovule is a lateral organ finally differentiated from the terminating floral meristem in rice. Dev Biol 351:208-216.

https://doi.org/10.1016/j.ydbio.2010.12.006

65. Yang Z, Chen Z, Peng Z, Yu Y, Liao M, Wei S (2017) Development of a high-density linkage map and mapping of the three-pistil gene (Pis1) in wheat using GBS markers. BMC Genomics 18:567. https://doi.org/10.1186/s12864-017-3960-7

66. Yao S-G, Ohmori S, Kimizu M, Yoshida H (2008) Unequal genetic redundancy of rice PISTILLATA orthologs, OsMADS2 and OsMADS4, in lodicule and stamen development. Plant Cell Physiol 49:853-857

67. Yu ZY, Luo Q, Peng ZS, Wei SH, Yang ZJ, Yamamoto N (2020) Genetic mapping of the three-pistil gene Pis1 in an F2 population derived from a synthetic hexaploid wheat using multiple molecular marker systems. Cereal Res Commun 49:31-36. https://doi.org/10.1007/s42976-020-00078-1

68. Zhang J, Zhang J, Liu W, Wu X, Yang X, Li X, Lu Y, Li L (2016) An intercalary translocation from Agropyron cristatum 6P chromosome into common wheat confers enhanced kernel number per spike. Planta 244:853-864. https://doi.org/10.1007/s00425-016-2550-2

69. Zhao T, Ni Z, Dai Y, Yao Y, Nie X, Sun Q (2006) Characterization and expression of 42 MADS-box genes in wheat (Triticum aestivum L.). Mol Genet Genomics 276:334-350.

https://doi.org/10.1007/s00438-006-0147-3

70. Zhu T, Wang L, Rimbert H, Rodriguez JC, Deal KR, De Oliveira R, Choulet F, Keeble-Gagnere G, Tibbits J, Rogers J, Eversole K, Appels R, Gu YQ, Mascher M, Dvorak J, Luo MC (2021) Optical maps refine the bread wheat Triticum aestivum cv. Chinese Spring genome assembly. Plant J 107:303-314. https://doi.org/10.1111/tpj.15289

71. Zhu X, Ni Y, He R, Jiang Y, Li Q, Niu J (2019) Genetic mapping and expressivity of a wheat multi-pistil gene in mutant 12TP. Journal of Integrative Agriculture 18:532-538. https:// doi.org/10.1016/s2095$3119(18) 61935-5$

\section{Figures}



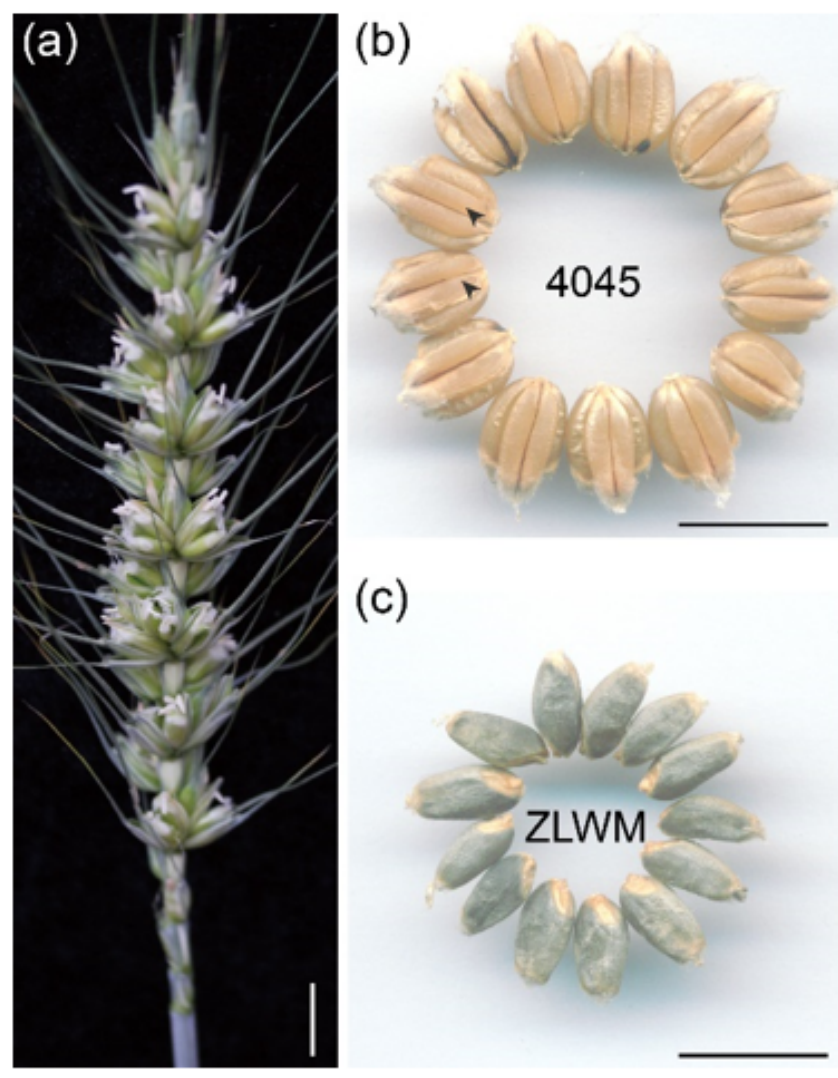

(d)

(c)

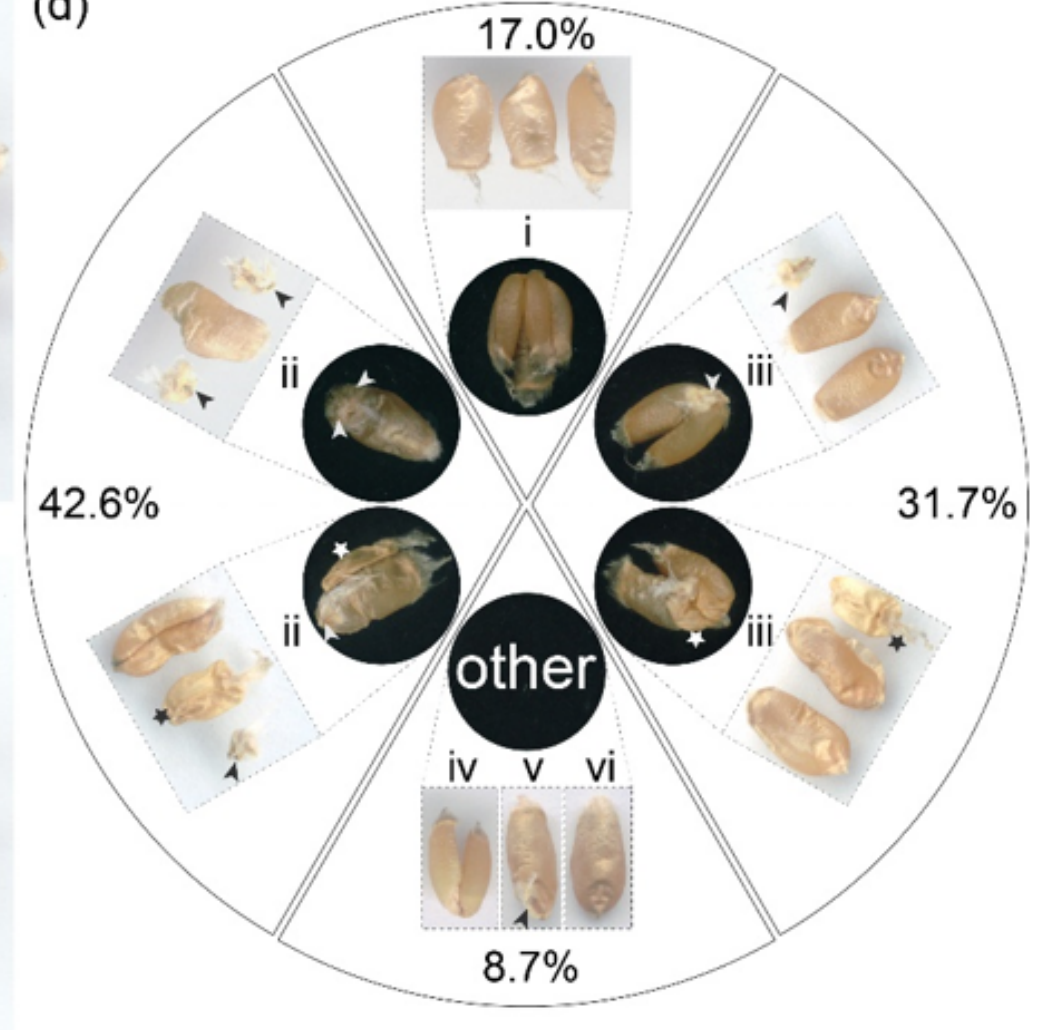

Figure 1

Spike and grain morphologies of the tri-pistil wheat, 4045, and blue-aleurone wheat ZLWM.

(a) Spike of 4045 . Bar $=1 \mathrm{~cm}$. (b) Grains of 4045 . The grains that is closer to the readers (as indicated by arrows) were larger than the two that are far from readers. Bar $=1 \mathrm{~cm}$. (c) Grains of ZLWM. Bar $=1 \mathrm{~cm}$. (d) Different grain types of 4045 and their proportions. i - vi indicate three grains, 1 normal 2 aborted grains, 2 normal 1 aborted grains, 2 normal grains , 1 normal 1 aborted and 1 normal floret types of the grains, respectively. Arrows indicate un-developed pistils while stars indicate un-filled grains. Percentages indicate proportions of every grain type. 


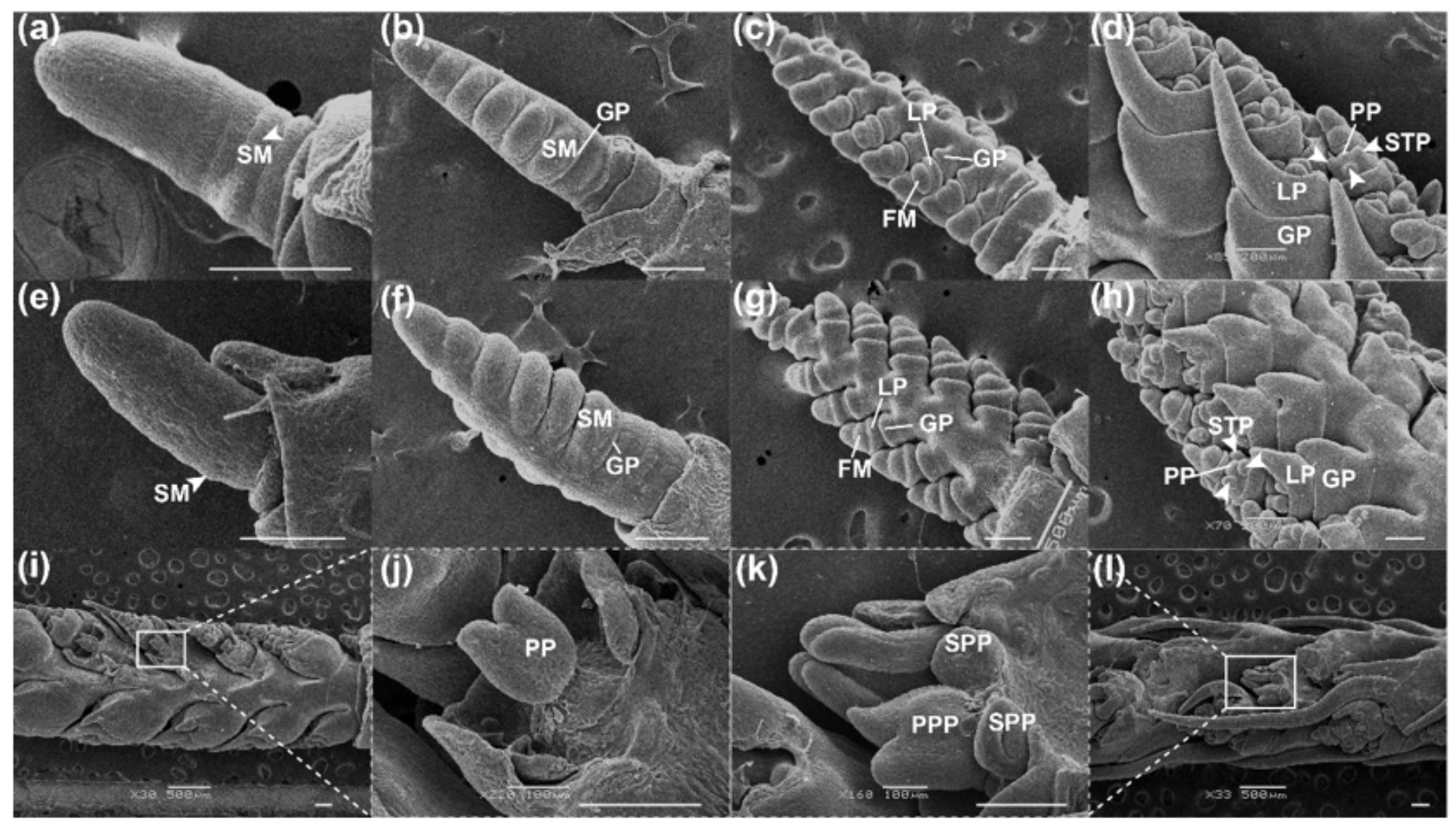

\section{Figure 2}

Comparisons of morphological features of young spikes between ZLWM (a-d, i,j) and 4045 (e-h, k, I).

Young spike morphological features at double ridge (DR) stage (a and e), glume differentiation (GD) stage (b and f), floret meristem (FM) stage ( $c$ and g), anther primordia (AM) stage ( $d$ and $h$ ) and tetrads stage (TS) (i-l) were observed and imaged. $\mathrm{j}$ and $\mathrm{k}$ denote enlarged views of white boxes in $\mathrm{i}$ and $\mathrm{l}$, respectively. SM: spikelet meristem; GP: glume primordium; LP: Lemma primordium; FM: floret meristem; PP: pistil primordium; STP: Stamen primordium; PPP: primary pistil primordium; SPP: secondary pistil primordium. Bars $=200$ um. 


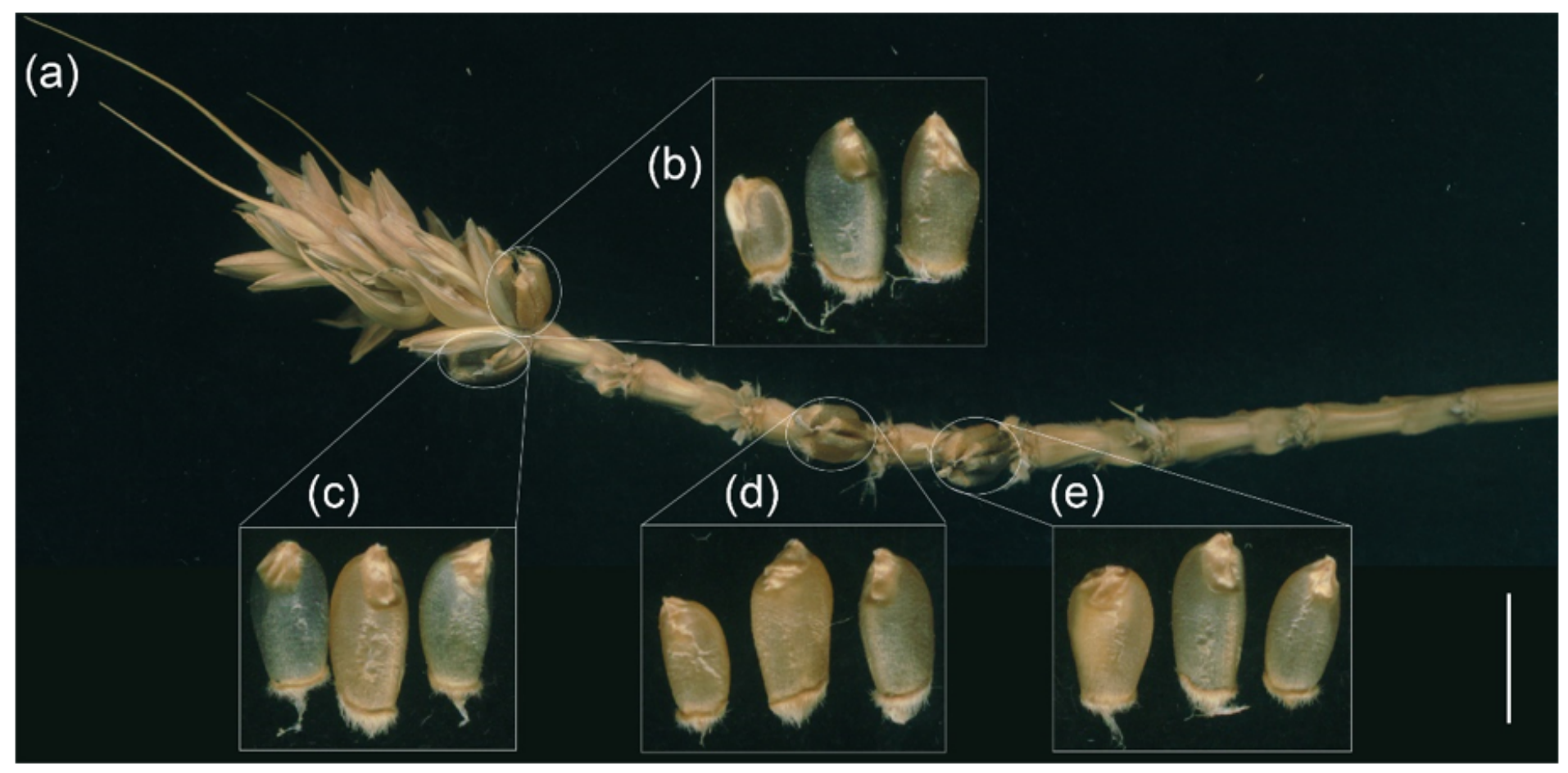

\section{Figure 3}

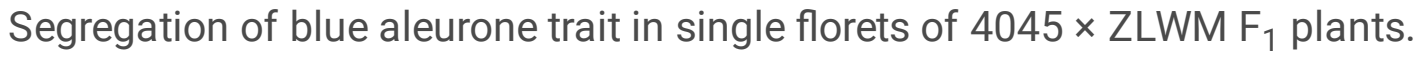

(a) An example of spikes of $F_{1}$ plants. (b-e) Different color combinations were observed in tri-grains. Trigrain b comprised white, dark blue and light blue (from left to right. Note that the white grain looked bluish because the seed was very thin and the black background went through it) grains; $c, d$ and $e$ comprised one white, two dark blue; one light blue, two white; and one white, two light blue grains, respectively. Panels show the grains that were dissected and enlarged from the three seeds of each floret in the circles. Bar for the spike $=1 \mathrm{~cm}$. 




\section{Figure 4}

Mapping and fine mapping of the TRP locus.

(a) Genetic linkage map of chromosome 2D-3. (b) Fine mapping of TRP using $F_{2}$ individuals. (c) Fine mapping of TRP using $\mathrm{F}_{2: 3}$ individuals. Numbers and genotypes of recombinants are shown the right in (b) and (c): The tri-pistil and single pistil image represents tri-pistil and single pistil phenotypes, respectively. Their combinations represent a heterozygous phenotype. Different types of recombinants are indicated on the left. 
(a)

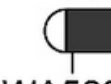

IWA5206-10

(b)

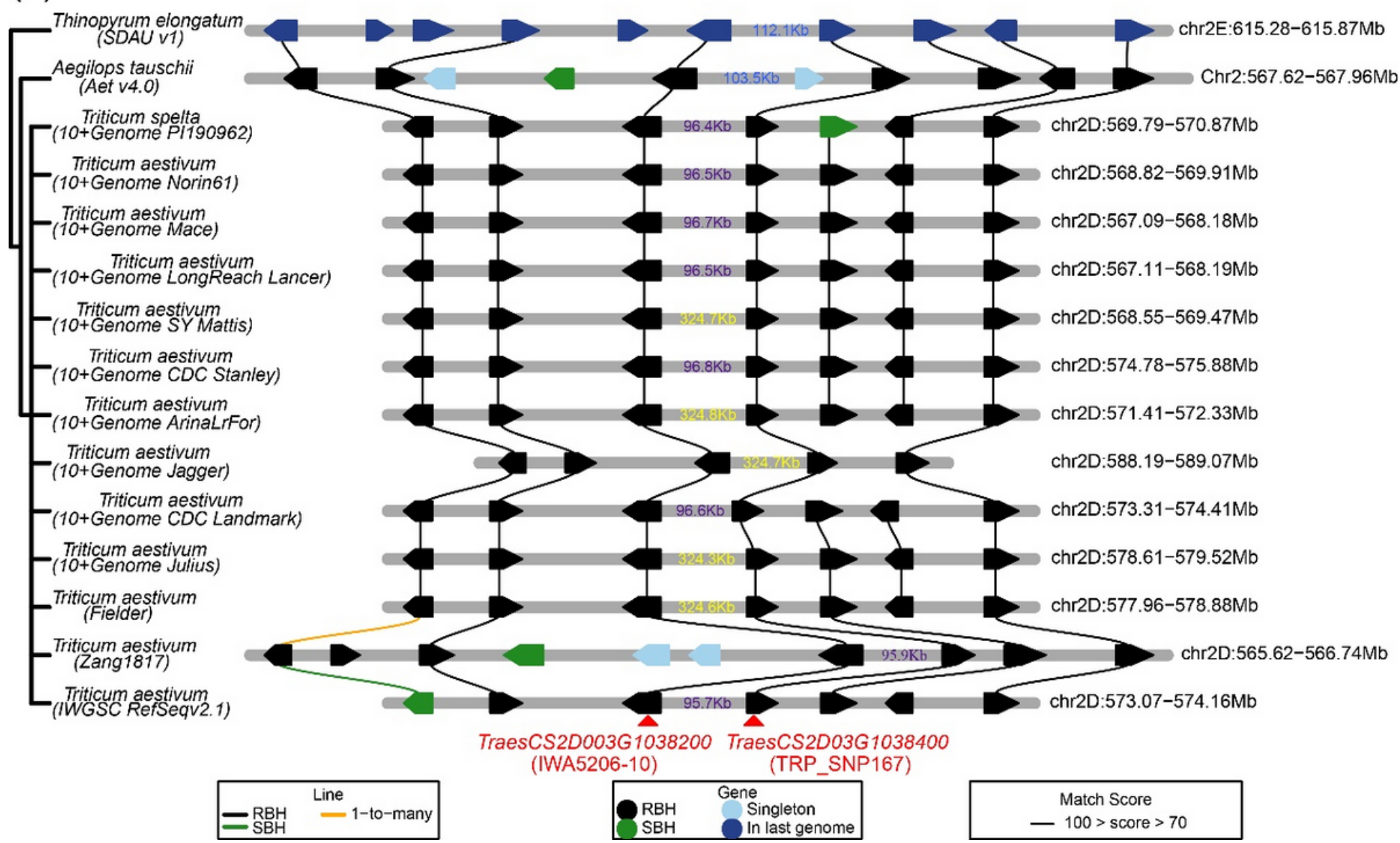

Figure 5

Sequence analysis of the mapping interval.

(a) TE distribution in mapping interval. (b) Genome collinearity analysis of mapping interval among different wheat and related species. Collinearity based cluster is shown on the left, while the positions of intervals are shown on the right. RBH: Reciprocal best hits, SBH: Single-side best hits (Chen et al. 2020b). 

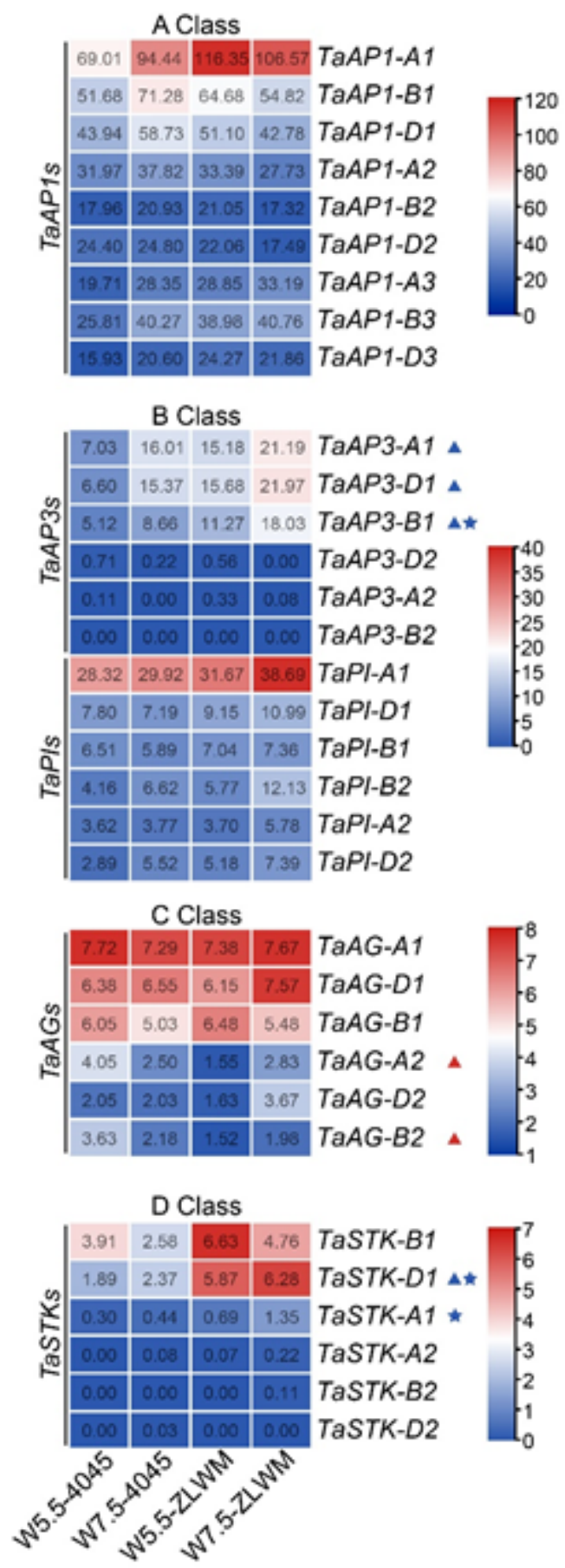

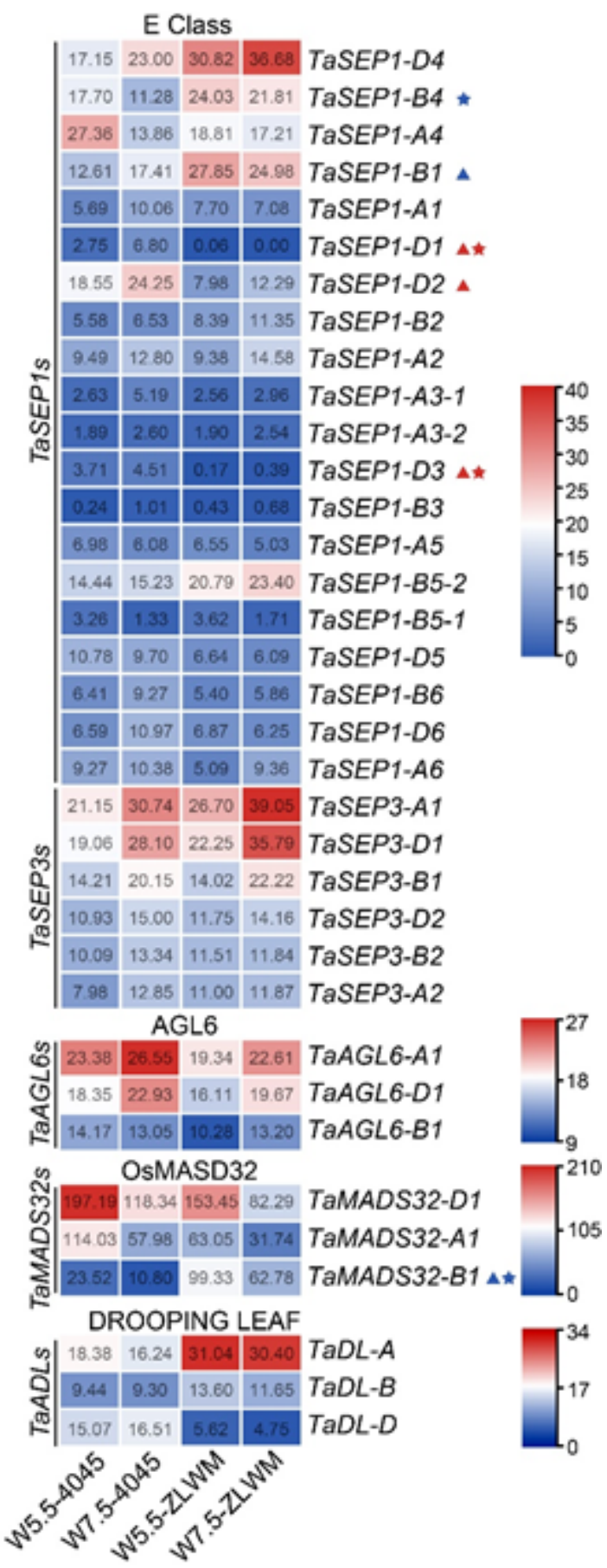

\section{Figure 6}

Transcriptional analysis of floral homeotic genes of young spikes in 4045 and ZLWM.

The heatmap showing FPKM values of 65 identified floral homeotic genes detected from young spikes of 4045 and ZLWM at W5.5 and W7.5 stages by RNA-seq. 
(a)

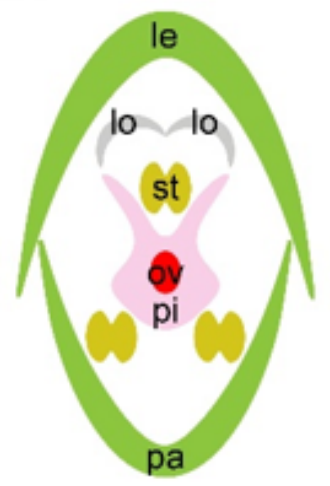

(c)

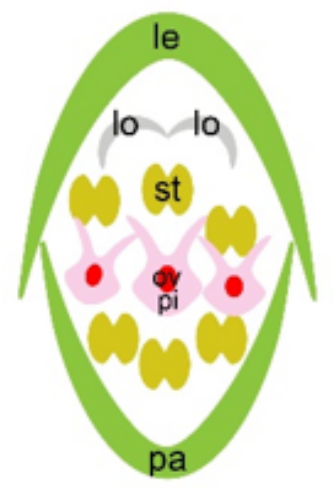

Normal

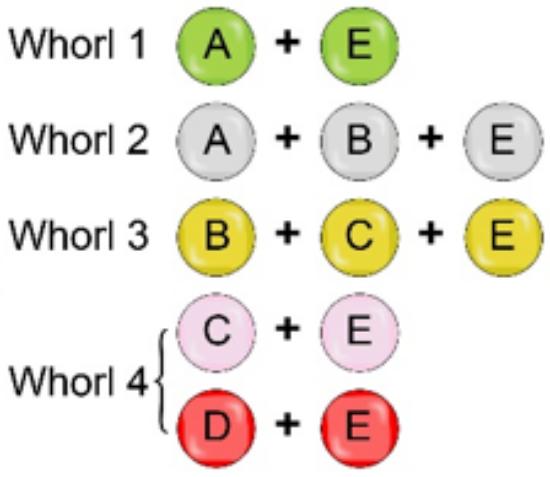

IFONI

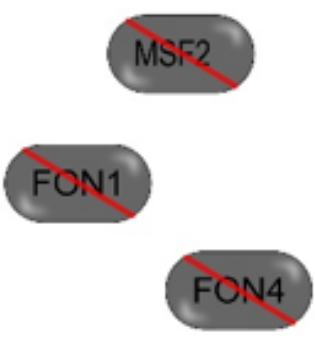

(b)

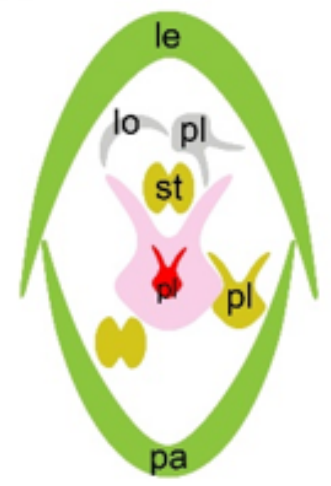

(d)

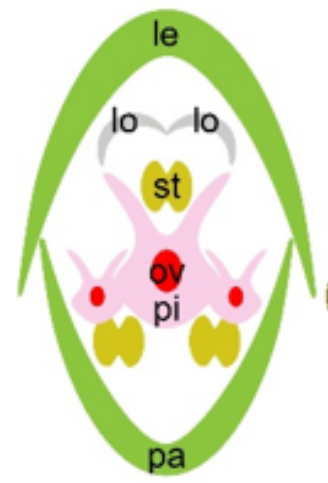

Pistillody

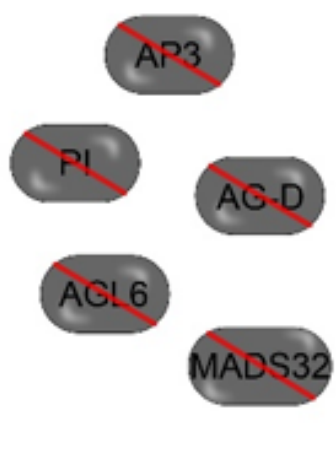

PRPNI

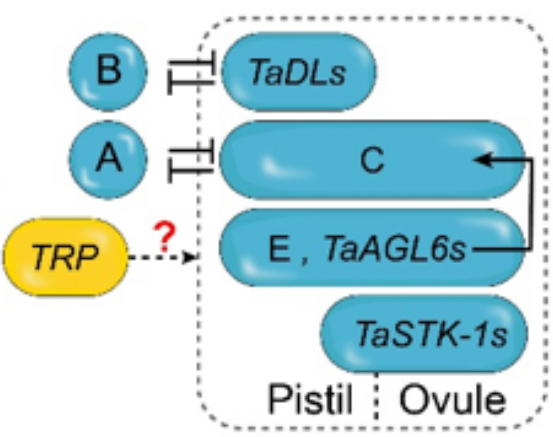

Figure 7

Models for different types of pistil number mutants in wheat (or rice).

(a) Structures of normal flowers and contributions of floral homeotic genes to the floral architecture. Different colors indicate floral organs in different whorls and their determinant genes. (b) Knockout or knockdown of AP3-, PI-, AG- (D class), AGL6-like or MADS32 proteins caused pistillody. (c) Structures of indefinite-floral-organ-number-increase (IFONI) flowers caused by silencing of proteins such as MSF, FON1 or FON4. (d) Structures of precisely-regulated-pistil-number-increase (PRPNI) flowers and a possible model for specifications of PRPNI pistils. Le: lemma; pa: palea; lo: lodicule; st: stamen; pi: pistil; pl:

pistillody; ov: ovule. Note: in some of the mutants in (c) and (d), the development of other floral organs was also influenced. This model only presents pistil and stamen alterations.

\section{Supplementary Files}

This is a list of supplementary files associated with this preprint. Click to download.

- Supplementarymaterials.pdf 